\title{
Characterization and Persistence of Actinophage RP2 Isolated from Streptomyces rimosus ATCC 10970
}

\author{
By D. HRANUELI, JASENKA PIGAC AND MARGARETA VEŠLIGAJ \\ PLIVA Pharmaceutical and Chemical Works, Zagreb, Yugoslavia
}

(Received 26 September 1978; revised 30 January 1979)

\begin{abstract}
While searching for true lysogens among oxytetracycline-producing Streptomyces rimosus strains, free phage particles were detected and isolated from a liquid culture of $S$. rimosus ATCC 10970 (R7). The actinophage, designated RP2, appears to be a typical temperate DNA phage producing turbid plaques on the sensitive strain $S$. rimosus R6. Electron microscopic examination of RP2 lysates showed that it belongs to group B of Bradley's morphological classification. The rate of RP2 adsorption at $28{ }^{\circ} \mathrm{C}$ appeared to be low. The length of the latent period was about $6 \mathrm{~h}$ and the average burst size about 120 phage particles.

The lysogenic nature of the host-virus system described was established on the basis of the following characteristics: spontaneous lysis frequency of $2 \times 10^{-6}$ per cell, resistance to curing with phage-specific antiserum, spontaneous curing frequency of less than $0.05 \%$ and immunity to superinfection with the homologous phage. Clear-plaque mutants of RP2, which failed to lysogenize sensitive cultures, arose at a frequency of $10^{-5}$.
\end{abstract}

\section{INTRODUCTION}

The first reports of the occurrence of true lysogeny in actinomycetes appeared simultaneously from three independent laboratories in 1956. It was soon established that most industrial cultures of antibiotic-producing streptomycetes were lysogenic or pseudolysogenic. The distribution of lysogenic Streptomyces species in culture collections has since been extensively studied especially in relation to antibiotic production (Welsch, 1969). However, the genetically well-characterized strain Streptomyces coelicolor A3(2) (Sermonti, 1969; Hopwood et al., 1973) appears to be the only actinomycete in which the genetic control of lysogeny has been investigated. Lomovskaya et al. (1970) were the first to describe a temperate phage isolated from $S$. coelicolor A3(2), while Dowding \& Hopwood (1973) reported the isolation of the free virion VP5, capable of lysogenizing the same strain.

While searching for true lysogens among the oxytetracycline-producing S. rimosus strains, we detected free phage particles in the liquid culture of S. rimosus ATCC 10970 (R7). In an attempt to establish this strain and its phage as a host-virus model system for investigating the impact of lysogeny on the industrial production of antibiotics, it has been necessary to grow and characterize the newly detected phage. In this report we describe the conditions necessary for its assay, propagation and preservation, as well as some of the phage characteristics, and show that $S$. rimosus, which, after $S$. coelicolor, is genetically the best known Streptomyces species (Alačević, 1969; Friend \& Hopwood, 1971; Alačević et al., 1973) harbours a prophage (designated RP2) in a truly lysogenic state. 


\section{METHODS}

Bacterial strains. Two independent wild-type isolates of Streptomyces rimosus were used: the lysogenic strain ATCC 10970 (R7), and the non-lysogenic strain R6 obtained from the Culture Collection of the Faculty of Technology, Zagreb. Both were maintained on agar plates for $10 \mathrm{~d}$ at $28^{\circ} \mathrm{C}$, and well-separated colonies were used for liquid culture propagation. Mycelium was incubated with shaking in experiments to determine growth curves.

Media. Complete medium (CM) contained ( $\mathrm{g}^{-1}$ in distilled water): malt extract (Difco), 10; yeast extract (Difco), 4 ; glucose, 4. Complete agar (CA) was complete medium solidified by the addition of $2 \%(\mathrm{w} / \mathrm{v})$ agar (Difco); soft agar contained only $0.7 \%$ agar. Liquid medium (LM) contained ( $\mathrm{g}^{-1}$ in distilled water): corn steep liquor (approx. 50\% solid), 16; dextrin, 40; $\mathrm{CaCO}_{3}, 7 ;\left(\mathrm{NH}_{4}\right)_{2} \mathrm{SO}_{4}, 2$. Phage lysates were prepared and diluted in nutrient broth (Difco). All media and diluents were adjusted to pH $7 \cdot 2$ after sterilization.

Phage assay. In the soft agar overlay technique (Adams, 1959), sensitive cells $(0.5 \mathrm{ml})$ from the earlystationary phase [approx. $2 \times 10^{9}$ colony-forming units (c.f.u.) $\mathrm{ml}^{-1}$ ] were mixed in soft agar with $0 \cdot 1 \mathrm{ml}$ samples of diluted phage lysates, poured on the agar base layer and incubated at $28{ }^{\circ} \mathrm{C}$ for 2 to $3 \mathrm{~d}$.

Lysate preparation. Lysates prepared by the confluent plate method (Eisenstark, 1967) contained about $10^{10}$ to $10^{11}$ plaque-forming units (p.f.u.) $\mathrm{ml}^{-1}$ and were sterilized by filtering through $25 \mathrm{~mm}$ Millipore filters (pore size $0.45 \mu \mathrm{m}$ ) or through Eerkefeld filters.

When necessary, lysates were concentrated and partially purified as follows. After centrifuging for $70 \mathrm{~min}$ in a WKF G420 Winkel Rotor $(6 \times 100 \mathrm{ml})$ at $17000 \mathrm{rev} . \mathrm{min}^{-1}\left(r_{\max } 64200 \mathrm{~g}\right)$, pellets were resuspended in

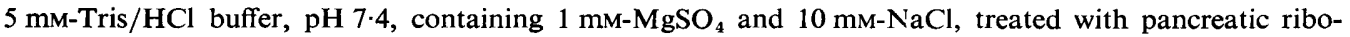
nuclease and deoxyribonuclease I (Boehringer) and then recentrifuged twice more. Concentrated phages were purified by 'rate zonal' centrifugation through a discontinuous gradient of sucrose by banding the phage at $17500 \mathrm{rev} . \mathrm{min}^{-1}\left(r_{\mathrm{av}} .31157 \mathrm{~g}\right)$ for $1.5 \mathrm{~h}$ in the Swingout-Rotor $(3 \times 34 \mathrm{ml})$ of WKF G420 centrifuge. The phage band was diluted 10 -fold with Tris/ $\mathrm{HCl}$ buffer and recentrifuged. Ultraviolet absorption spectra of purified preparations were determined using a Pye Unicam SP8-100 ultraviolet spectrophotometer.

Electron microscopy. Droplets of purified phage suspension were negatively stained with neutral $2 \%(\mathrm{w} / \mathrm{v})$ potassium phosphotungstate solution on carbon-coated copper grids. Excess suspending fluid was removed with a piece of filter paper, and the preparation was air-dried. Grids were examined in a Siemens Elmiskop I electron microscope.

Adsorption. Adsorption rates were established by measuring the phage particles from the supernatant fraction of adsorption mixtures according to Adams (1959). Sensitive cells from the exponential phase of growth (approx. $2 \times 10^{8}$ c.f.u. $\mathrm{ml}^{-1}$ ) were infected with phage at a low multiplicity $(<0 \cdot 1)$ and incubated at $28^{\circ} \mathrm{C}$ with shaking. Samples were withdrawn after $7 \cdot 5,15,30,45$ and $60 \mathrm{~min}$, centrifuged and tested.

One-step growth experiment (Adams, 1959). Phage was added to exponentially growing sensitive cultures to give a low multiplicity of infection (about $0 \cdot 1$ ). After $60 \mathrm{~min}$ adsorption in a mixture with $\mathrm{KCN}$ (final concentration $0.1 \mathrm{~mm}$ ), free phage particles were eliminated by adding antiserum (1:50). After $15 \mathrm{~min}$, the infected cells were diluted $10^{-3}$ (first growing flask) or $10^{-5}$ (second growing flask) and incubated at $28^{\circ} \mathrm{C}$ with shaking. Samples were assayed at $30 \mathrm{~min}$ intervals for plaque forming ability.

Nucleic acid determination. To determine the type and configuration of nucleic acid in a phage particle, we used the method of Bradley (1966) with the double-stranded DNA coliphage $\lambda$ and the single-stranded RNA coliphage $f_{2}$ (kindly supplied by Dr E. Salaj-Smic) as controls.

Deoxyribose was measured using the diphenylamine reaction (Burton, 1956), and ribose by the orcinol reaction (Dische, 1953).

Ultraviolet-irradiation. A suitably diluted cell suspension of $S$. rimosus $\mathbf{R} 7$ was plated on CA and irradiated with a Philips TUV15 germicidal lamp. The dose rate, measured by a dosimeter with a Latarjet No. 111 photoelectric cell, was $4 \cdot 1 \mathrm{~J} \mathrm{~m}^{-2} \mathrm{~s}^{-1}$. All operations were carried out under yellow light from a G.E. 'Gold' fluorescent lamp. Irradiated cells were incubated in the dark at $28^{\circ} \mathrm{C}$ for $48 \mathrm{~h}$.

Preparation of RP2 antiserum. This was done essentially as described by Adams (1959), except that Freund's incomplete adjuvant was used.

\section{RESULTS}

Isolation and morphology of RP2. An actinophage, which we designated RP2, was isolated from a liquid culture of Streptomyces rimosus R7 plated on a lawn of S. rimosus R6; its plaques on R6 had a turbid centre surrounded by a clear halo, and an average diameter, when well-developed, of between 3 and $5 \mathrm{~mm}$ (Fig. 1). 


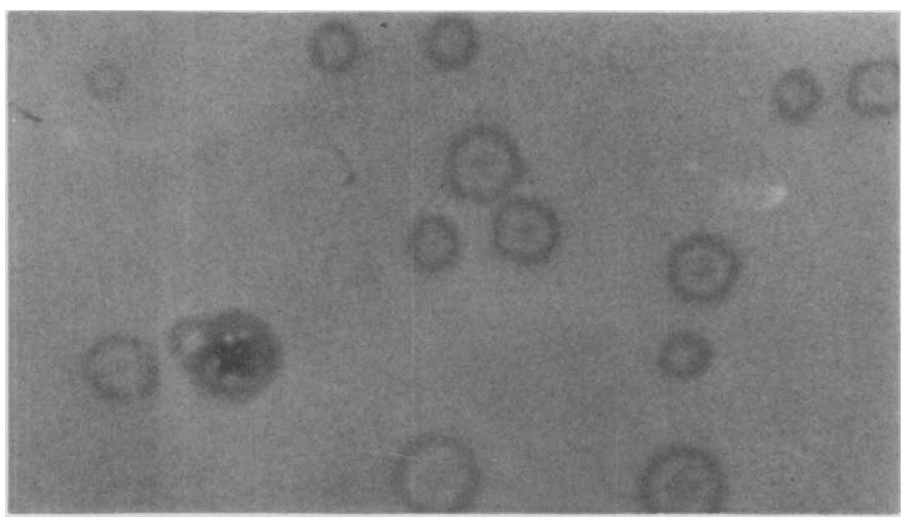

Fig. 1. Morphology of RP2 plaques on Streptomyces rimosus R6 after $4 \mathrm{~d}$. An example of a clearplaque mutant can be seen. (Magnification $\times 2$ ).

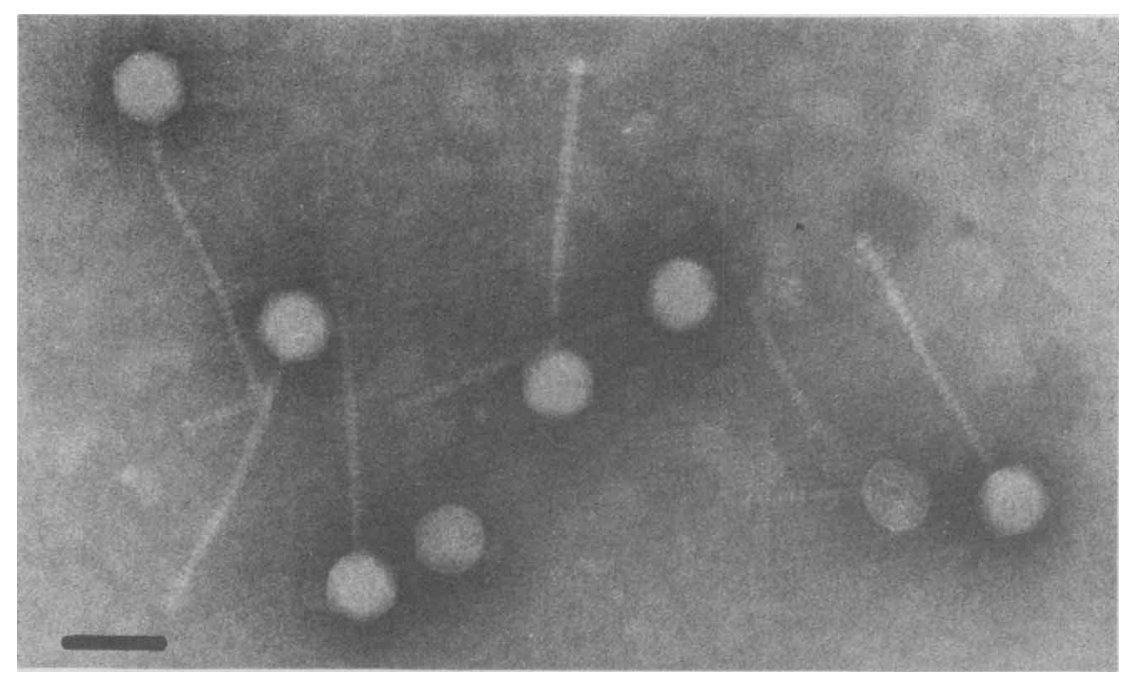

Fig. 2. Electron micrograph of RP2 particles negatively stained with potassium phosphotungstate. Bar marker represents $100 \mathrm{~nm}$.

Electron microscopic examination of RP2 lysates showed particles with a hexagonal head and a long, flexible, non-contractile tail (Fig. 2). Measurements of 50 particles indicated an average head diameter of $71.5 \pm 1.5 \mathrm{~nm}$, a tail length of $250 \pm 4.0 \mathrm{~nm}$ and a tail width of $16 \pm 2.0 \mathrm{~nm}$. There appeared to be a special fixation structure in the distal extremity of tails, but this was not clearly distinguishable on complete particles.

Influence of environmental factors on RP2 stability and efficiency of plating. To determine the stability of RP2 in liquid, $0.1 \mathrm{ml}$ samples of RP2 lysate were added to $10 \mathrm{ml}$ of various salt solutions and buffers, and after $24 \mathrm{~h}$ incubation the resulting mixtures were assayed for viable phage (Table 1). Actinophage RP2 was stable in most of the salt solutions tested, but irreversible inactivation occurred in $100 \mathrm{mM}-\mathrm{NaCl}$ and in $5 \mathrm{~mm}$ phosphate and citrate/ phosphate buffers.

$\mathrm{RP} 2$ was stable in $5 \mathrm{~mm}$-Tris/ $\mathrm{HCl}$ buffer over the $\mathrm{pH}$ range 7 to 9 . Tris $/ \mathrm{HCl}$ buffer, $\mathrm{pH}$ $7 \cdot 4$, supplemented with $1 \mathrm{mM}-\mathrm{MgSO}_{4}, 10 \mathrm{mM}-\mathrm{NaCl}$ and $10 \mu \mathrm{g}_{\text {gelatine }} \mathrm{ml}^{-1}$ was found to be satisfactory for storage of the phage for at least 2 years.

The effect of $\mathrm{Na}^{+}, \mathrm{Mg}^{2+}$ and $\mathrm{Ca}^{2+}$ on the efficiency of plating (e,o.p.) of RP2 was determined on $\mathrm{CA}$ and $\mathrm{CA}$ containing $5 \mathrm{~mm} \mathrm{NaCl}, \mathrm{MgSO}_{4}$ or $\mathrm{Ca}\left(\mathrm{NO}_{3}\right)_{2}$. The relative e.o.p. 
Table 1. Stability of actinophage RP2 in various diluents

Phage lysate $(0 \cdot 1 \mathrm{ml})$ was added to $10 \mathrm{ml}$ diluent and the mixture was assayed for viable phage after $24 \mathrm{~h}$.

\begin{tabular}{lcc}
\multicolumn{1}{c}{ Diluent } & Concn (mM) & $\begin{array}{c}\text { Phage RP2 } \\
\text { (p.f.u. ml }\end{array}$ \\
$\begin{array}{l}\text { Nutrient broth } \\
\mathrm{MgSO}_{4}\end{array}$ & $100-1$ & $1.4 \times 10^{8}$ \\
$\mathrm{Ca}\left(\mathrm{NO}_{3}\right)_{2}$ & 1 & $1.8 \times 10^{8}$ \\
$\mathrm{Ca}\left(\mathrm{NO}_{3}\right)_{2}$ & $10-1$ & $5.0 \times 10^{7}$ \\
$\mathrm{NaCl}$ & 100 & $1.6 \times 10^{8}$ \\
$\mathrm{NaCl}$ & $10-1$ & $2.5 \times 10^{8}$ \\
Tris/ $\mathrm{HCl}$ buffer & 5 & $2.0 \times 10^{8}$ \\
Phosphate buffer & 5 & $2.0 \times 10^{8}$ \\
Citrate/phosphate buffer & 5 & $1.4 \times 10^{6}$ \\
& & $3.3 \times 10^{5}$
\end{tabular}

values obtained with $\mathrm{Na}^{+}, \mathrm{Mg}^{2+}$ and $\mathrm{Ca}^{2+}$ were $0 \cdot 9,1 \cdot 2$ and $1 \cdot 1$, respectively, indicating that the e.o.p. was not affected by these cations.

Effect of the age of the host culture on the plating efficiency of RP2. Streptomyces rimosus R6 was grown in LM and suspensions corresponding to the early-exponential, exponential, late-exponential and stationary phases of growth were tested. The number of R6 c.f.u. $\mathrm{ml}^{-1}$ increased from about $10^{7}$ to $10^{9}$ during this time. The effect of the density of R6 in the soft agar on RP2 e.o.p. was therefore investigated. Results showed that the phage e.o.p. was independent of the number of R6 c.f.u. as long as a lawn of the indicator strain was formed. However, RP2 plaque morphology was affected. Typical, fully developed plaques were formed only when soft agar was inoculated with more than $10^{8}$ c.f.u. $\mathrm{ml}^{-1}$. RP2 e.o.p. was not markedly influenced by the host culture age. Therefore, $S$. rimosus R6 mycelium from the stationary phase of growth was used routinely, giving a smooth uniform lawn and typical plaque morphology.

Adsorption. Adsorption rate constants were determined for S. rimosus strains R6 and R7 (Fig. 3). In the absence of a host, there was no loss of viable phage during 60 min incubation. When logarithms of the percentage of unadsorbed phage were plotted against time, the curves were linear between 0 and $30 \mathrm{~min}$ for both strains, after which the adsorption rates appeared to fall. Adsorption rate constants were $8.8 \times 10^{-11}$ and $1.1 \times 10^{-10} \mathrm{ml} \mathrm{min}^{-1}$ for R6 and R7, respectively, showing a relatively low rate of attachment under these conditions.

Attempts were made to desorb any reversibly adsorbed particles. However, less than $0.1 \%$ of reversibly adsorbed particles were observed, either on diluting the adsorption mixture 100 -fold in plain broth before separation of free phages, or by looking for eluted particles after resuspending the sediment of an adsorption mixture in nutrient broth.

One-step growth experiment. The one-step growth curve of RP2 at $28{ }^{\circ} \mathrm{C}$ gives a value of $6 \mathrm{~h}$ for the minimum latent period, followed by a $4 \mathrm{~h}$ period of increase (Fig. 4). The average burst size was 100 to 120 phage particles.

Since the recovery of infective centres at a multiplicity of infection of 0.1 was very low under the conditions used, it seemed likely that filaments of various lengths adsorbed and inactivated from one to several phage particles; the resulting complex would be identifiable as only one infective centre. However, the occurrence of abortive infections has not been ruled out.

Determination of RP2 nucleic acid type. A concentrated and purified RP2 preparation exhibited a high degree of homogeneity. Its ultraviolet absorption spectrum showed a minimum at $241 \mathrm{~nm}$ and a maximum at $261 \mathrm{~nm}$. The ratio of absorbance of 260/280 nm was $1 \cdot 24$.

The type and configuration of RP2 nucleic acid was determined by fluorescent staining with acridine orange (Bradley, 1966). Comparison with the double-stranded DNA coli- 


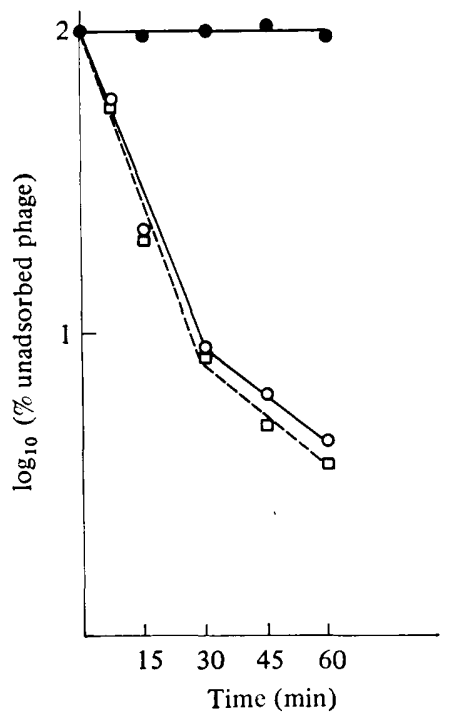

Fig. 3

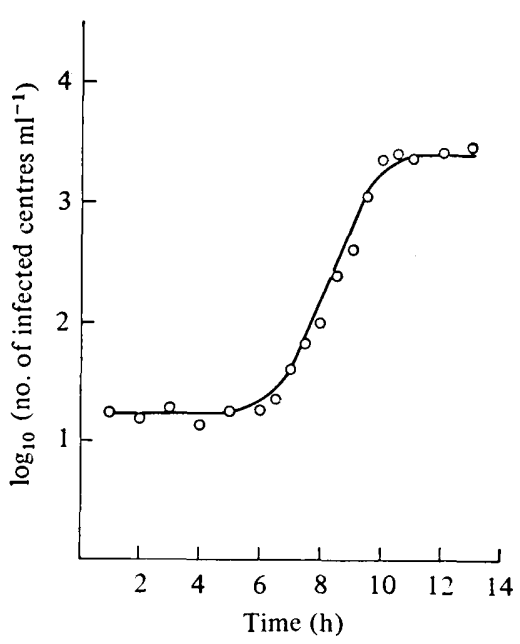

Fig. 4

Fig. 3. Attachment of RP2 to Streptomyces rimosus R6 (O) and R7 ( $\square$ ). (O, Control, without host.)

Fig. 4. One-step growth curve of RP2 on Streptomyces rimosus R6 at $28^{\circ} \mathrm{C}$.

phage $\lambda$ and the single-stranded RNA coliphage $f_{2}$ indicated that the actinophage RP2 nucleic acid was double-helical DNA. The results were confirmed by estimations of deoxyribose and ribose in the preparation, which corresponded to $62 \mu \mathrm{g} \mathrm{DNA} \mathrm{ml}^{-1}$ and $2 \mu \mathrm{g}$ RNA $\mathrm{ml}^{-1}$.

Host-range. The ability of RP2 to form plaques on 23 Streptomyces species was determined. The e.o.p. of RP2 was $<10^{-9}$ for each host except $S$. rimosus R6. Its host-range therefore appears to be quite narrow.

Spontaneous phage release. A suspension of $S$. rimosus $\mathrm{R} 7$ from a liquid culture was centrifuged at low speed and then the supernatant was membrane-filtered and assayed on strain R6 for free phage. Suitable dilutions of the washed suspension (approx. $1 \times 10^{9}$ c.f.u. $\mathrm{ml}^{-1}$ ) were plated and immediately overlaid with R6 to test for spontaneous phage release. The plaque counts from three independent experiments demonstrated that supernatants of strain R7 always contained about $3 \times 10^{3}$ free phage particles $\mathrm{ml}^{-1}$. However, 30 to $40 \%$ of colonies derived from the plated cells released phage spontaneously in less than $3 \mathrm{~d}$. When further platings of R7 cells were overlaid with the sensitive strain R6 after 5 to $6 \mathrm{~d}$ growth and incubated for a further 2 to $3 \mathrm{~d}$, every colony was surrounded by a zone of phage lysis.

The kinetics of spontaneous production of RP2 in a liquid culture of S. rimosus R7 is shown in Fig. 5. The maximum number of spontaneously produced phage was $4.8 \times 10^{5}$ p.f.u. $\mathrm{ml}^{-1}$ seen after $48 \mathrm{~h}$ incubation. At that time, cells were in the stationary phase of growth and the viable cell count was about $2 \times 10^{9}$ to $3 \times 10^{9}$ c.f.u. $\mathrm{ml}^{-1}$. After prolonged incubation the phage titre continuously decreased. Since the burst size of RP2 was about 100 particles (c.f.u. $)^{-1}$, the spontaneous lysis frequency of R7 was of the order of $10^{-6}$ (c.f.u. $)^{-1}$ at $48 \mathrm{~h}$.

When spontaneous phage release was tested in the presence of phage-specific antiserum, no free phage was detected. After removal of antiserum, phage were produced at the usual rate. Moreover, colonies obtained by streaking out from liquid cultures containing antiserum retained the ability to produce phage, providing further evidence of true lysogeny of S. rimosus $\mathbf{R} 7$. 


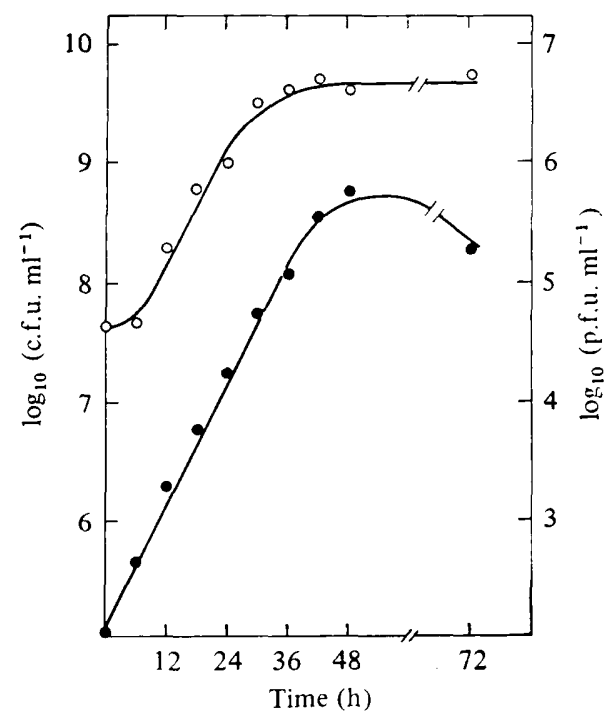

Fig. 5. Kinetics of spontaneous RP2 production by Streptomyces rimosus $\mathrm{R} 7$. The strain was grown in liquid medium $\left(1 \%\right.$ inoculum) with shaking at $28{ }^{\circ} \mathrm{C}$. Numbers of c.f.u. $(\bigcirc)$ and of free phage particles (O) were estimated at $6 \mathrm{~h}$ intervals.

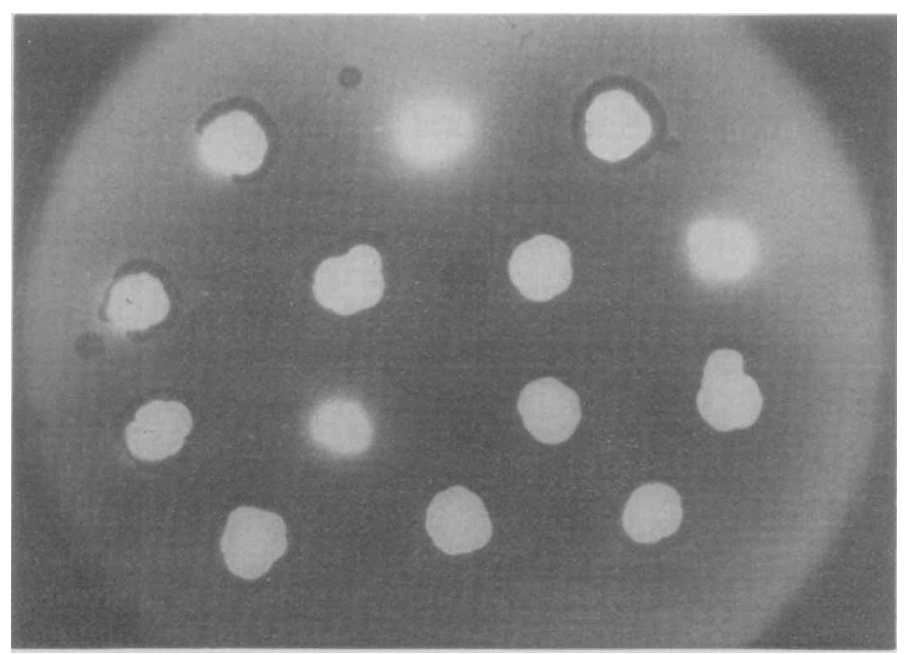

Fig. 6. Single colony isolates from Streptomyces rimosus $\mathrm{R} 7$ were inoculated on a 'master-plate' and overlaid with the phage-sensitive strain S. rimosus R6. The three colonies showing no sign of lysis were $\mathbf{R} 6$ isolates included as controls.

Clear-plaque mutants. These arose spontaneously on plates seeded with a large number of RP2 particles (Fig. 1) at an average frequency, tested by plating 10 wild-type plaques, of approx. $2 \times 10^{-5}$.

Sensitivity to homologous phage. Streptomyces rimosus $\mathrm{R} 7$ appeared to be immune to superinfection with RP2 and its clear-plaque mutants. Immunity to superinfection was also confirmed in all auxotrophic mutants of the strain R7 so far tested, although adsorption was normal.

Phage curing. The frequency of spontaneous curing of $S$. rimosus $\mathrm{R} 7$ cells from RP2 was tested by making serial single colony isolations. None of 2708 colonies overlaid with 
an indicator top layer after $3 \mathrm{~d}$ failed to produce phage (Fig. 6). Spontaneous curing was therefore $<0.05 \%$.

After ultraviolet treatment of mycelial fragments to $10^{-6}$ to $10^{-5}$ survival, about $0 \cdot 1 \%$ (3/2919) of colonies failed to produce phage. These were all immune to superinfection by RP2 although they could still adsorb it; presumably they carried a defective RP2 prophage.

\section{DISCUSSION}

Actinophage RP2 isolated from a liquid culture of Streptomyces rimosus R7 has been grown and partially characterized. Its morphology and double-stranded DNA content place it in group B of Bradley's morphological classification (Bradley, 1967). It is a tadpoleshaped particle, like most other actinophages (Welsch, 1969; Hopwood et al., 1973; Korn et al., 1978), apart from the tail-less actinophage $\phi 17$ (Bacq \& Horne, 1963) and rod-like nocardiophage described by Azarowitz et al. (1954).

General properties of the RP2 life-cycle were determined in one-step growth experiments. From the adsorption rate constants it was apparent that RP2 attachment was slow. This appears to be typical of all actinophages (Welsch, 1969), and different from other phagebacteria systems (Dowding, 1973). Although the latent period of actinophage-actinomycete systems is usually long (Welsch, 1969), RP2, with its $6 \mathrm{~h}$ latent period, is the slowest multiplying actinophage so far described.

Spontaneous release of RP2 particles from S. rimosus R7 occurred only in part of the population as shown by plating with the sensitive strain. Lomovskaya et al. (1972) and Dowding \& Hopwood (1973) observed that only a few per cent of $S$. coelicolor A3(2) spores plated gave rise to colonies releasing phage. The fact that about 30 to $40 \%$ of the R7 cells plated produced colonies releasing phage may be explained in terms of the faster growth of the lysogenic strain than the sensitive strain. In these experiments mycelial fragments were used instead of spores, which increased the growth rate of the lysogenic strain considerably.

In various lysogenic systems $10^{-5}$ to $10^{-2}$ cells per generation undergo spontaneous lysis (Adams, 1959). Since streptomycetes are growing in a complex mycelial form and thus do not have a defined generation time, spontaneous induction was calculated as the frequency of lysis among viable c.f.u. during the period of increase in phage production. The highest titre of RP2 free phage particles $\left(4 \cdot 8 \times 10^{5}\right.$ p.f.u. $\left.\mathrm{ml}^{-1}\right)$ is considerably lower than titres of free phages (up to $10^{10}$ p.f.u. $\mathrm{ml}^{-1}$ ) obtained in pseudolysogenic conditions (Bott \& Strauss, 1965). The value for spontaneous lysis frequency of about $10^{-6}$ (c.f.u) $)^{-1}$ calculated from these figures is probably a gross underestimate, but nevertheless is very low compared with values obtained in pseudolysogenic or carrier state systems (Bott \& Strauss, 1965).

Although liquid cultures of R7 always contained free phage, detectable lysis was not observed. Streptomyces rimosus R7 is thus immune to infection with the homologous phage RP2. This immunity was also shown by the inability of RP2 to form plaques when plated on the R7 strain.

The lack of spontaneous curing of R7 cells provides further evidence of the truly lysogenic nature of the host-virus system studied. The curing rate $(<0.05 \%)$ was very low in comparison with spontaneous curing frequencies of 30 to $90 \%$ among non-lysogenic phagecarrying strains (Bott \& Strauss, 1965; Baess, 1971).

It was impossible to cure the cells even after exposure to high doses of ultraviolet light. Although this procedure has proved successful in some cases (Zinder, 1958; Lomovskaya et al., 1971), we were unable to isolate a single cured variant out of 2919 colonies tested.

Final evidence of the true lysogeny of $S$. rimosus $\mathrm{R} 7$ comes from experiments using RP2-specific antiserum. The RP2 titre in successive liquid cultures remains remarkably constant if one takes into account the mycelial nature of actinomycetes. However, free 
phage readily disappears from cultures containing antiserum, while the transfer from antiserum-containing culture to plain broth immediately results in the production of RP2 particles. Moreover, R7 cells isolated from the antiserum-containing culture give rise to colonies spontaneously liberating phage.

Clear-plaque mutants arise spontaneously from RP2 wild-type stocks. The fact that these lose their ability to lysogenize sensitive cells but are still unable to lyse strains carrying the wild-type prophage suggests, by analogy with phage $\lambda$ (Hershey, 1971), that these mutations affect some steps of the lysogenization process. Similar mutants have been isolated from the $S$. coelicolor A3(2) temperate phages $\phi$ C31 and VP5 (Lomovskaya et al., 1970; Dowding $\&$ Hopwood, 1973). However, clear-plaque mutants of Bacillus subtilis phage SP10, which does not establish a stable relationship with the host, were reported (Kawakami \& Landman, 1968). Consequently, their appearance cannot be taken as proof of a truly lysogenic condition.

All RP2 characteristics reported here indicate that it is a typical temperate actinophage comparable to those already described. The knowledge of its properties as well as conditions necessary for its routine propagation and assay will facilitate further studies. The results proving true lysogeny in the RP2-S. rimosus $\mathrm{R} 7$ host-virus system will enable the study of prophage behaviour during the production of antibiotic in relation to inducibility, appearance of virulent mutants or other lytic factors.

The skilled technical assistance of M. Debelli, V. Horvat and M. Smolčić is gratefully acknowledged. We would like to thank Dr N. Ljubešić for electron micrograph preparation, Dr S. Petričević for antiserum preparation and Professors M. Alačević and G. Sermonti for critically reading the manuscript.

\section{REFERENCES}

Adams, M. H. (1959). Bacteriophages. New York: Wiley-Interscience.

AlaČEviĆ, M. (1969). Recombination in Streptomyces producing tetracyclines. In Proceedings of International Symposium on Genetics and Breeding of Streptomyces, pp. 137-145. Zagreb: Yugoslav Academy of Sciences and Arts.

Alačević, M., Strašek-VešligaJ, M. \& Sermonti, G. (1973). The circular linkage map of Streptomyces rimosus. Journal of General Microbiology 77, 173-185.

AzArowitz, E. N., ERICKSON, J. O. \& ARMEN, D. M. (1954). Information from the electron micrograph. Journal of the Biological Photographic Association 22, 49-52.

BACQ, C. M. \& Horne, R. W. (1963). Morphology of actinophage $\phi 17$. Journal of General Microbiology 32, 131-133.

BAEss, I. (1971). Report on a pseudolysogenic mycobacterium and a review of the literature concerning pseudolysogeny. Acta pathologica et microbiologica scandinavica 79, 428-434.

BotT, K. \& Strauss, B. (1965). The carrier state of Bacillus subtilis infected with the transducing bacteriophage SP10. Virology 25, 212-225.

BRADLEY, D. E. (1966). The fluorescent staining of bacteriophage nucleic acids. Journal of General Microbiology 44, 383-391.

Bradley, D. E. (1967). Ultrastructure of bacteriophages and bacteriocins. Bacteriological Reviews 31, 230-314.
Burton, K. (1956). A study of the conditions and mechanisms of the diphenylamine reaction for the colorimetric estimation of deoxyribonucleic acid. Biochemical Journal 62, 315-323.

Dische, Z. (1953). Qualitative and quantitative colorimetric determination of heptoses. Journal of Biological Chemistry 204, 983-987.

Dowding, J. E. (1973). Characterization of a bacteriophage virulent for Streptomyces coelicolor A3(2). Journalof General Microbiology 76, 163-176.

Dowding, J. E. \& Hopwood, D. A. (1973). Temperate bacteriophages for Streptomyces coelicolor A3(2) isolated from soil. Journal of General Microbiology 78, 349-359.

EISENSTARK, A. (1967). Bacteriophage techniques. Methods in Virology 1, 450-518.

Friend, E. J. \& Hopwood, D. A. (1971). The linkage map of Streptomyces rimosus. Journal of General Microbiology 68, 187-197.

Hershey, A. D. (1971). The Bacteriophage Lambda. New York: Cold Spring Harbor Laboratory.

Hopwood, D. A., Chater, K. F., Dowding, J. E. \& Vivian, A. (1973). Advances in Streptomyces coelicolor genetics. Bacteriological Reviews 37, $371-405$.

KawaKami, M. \& LANDman, O. E. (1968). Nature of the carrier state of bacteriophage SP10 in Bacillus subtilis. Journal of Bacteriology 95, 1804-1812.

Korn, F., Weingärtner, B. \& Kutziner, H. J. (1978). A study of twenty actinophages: mor- 
phology, serological relationship and host range. In Genetics of the Actinomycetales, pp. 251-270. Edited by E. Freerksen, I. Tarnok \& J.H. Thumim. Stuttgart \& New York: Gustav Fischer Verlag.

Lomovskaya, N. D., Mkrtumian, N. M. \& GosTIMSKAYA, N. L. (1970). Isolation and characterization of the actinophage of Streptomyces coelicolor. Genetika 6 (12), 135-137.

Lomovskaya, N. D., Emeljanova, L. K. \& AlikHANIAN, S. I. (1971). The genetic location of prophage on the chromosome of Streptomyces coelicolor. Genetics 68, 341-347.

Lomovskaya, N. D., Mkrtumian, N. M., GostimSKAYA, N. L. \& DANILENKo, V. N. (1972).
Characterization of temperate actinophage $\phi \mathrm{C} 31$ isolated from Streptomyces coelicolor A3(2). Journal of Virology 9, 258-262.

SERMONTI, G. (1969). Genetics of Antibiotic-producing Microorganisms. London \& New York: WileyInterscience.

WELSCH, M. (1969). Biology of actinophages. In Symposium on Genetics and Breeding of Streptomyces, Dubrovnik, pp. 43-62. Edited by M. Alačević \& G. Sermonti. Zagreb: Yugoslav Academy of Sciences and Arts.

ZINDER, N. D. (1958). Lysogenisation and superinfection immunity in Salmonella. Virology 5, 291-326. 